\title{
De la interioridad mental a la exterioridad corpórea: una lectura del asco en Beckett
}

Fecha de recepción: 10 de abril de 2021.

Fecha de aceptación: 14 de septiembre de 2021.

\begin{abstract}
Resumen
A partir de la lectura de "(W)Horoscope", seis poemas de Echo's Bones and Other Precipitates y "La mouche", en este trabajo se buscará plantear cómo el asco articula la relación que establece Samuel Beckett entre el mundo exterior: lo corpóreo, degradado, caduco, y la interioridad del pensamiento del sujeto melancólico que medita sobre la muerte. Este contraste se encuentra atravesado por distintas concepciones del asco que afectan tanto a la mente como al cuerpo. Nos detendremos en el asco en relación a los alimentos, a aquello que se ingiere y por lo tanto ingresa en el cuerpo y afecta la mente; en el asco como hastío y melancolía, que surge de un estado de inactividad que hace pensar en la caducidad y la decadencia; y desde allí se abordará la relación del asco con las concepciones cuerpo-cadáver, la degradación corpórea y la meditación sobre la muerte. Estos tres ejes permitirán ejemplificar cómo el interior y el exterior se conectan mediante lo repulsivo en los poemas de Beckett.
\end{abstract}

Palabras clave: Samuel Beckett, asco, melancolía, cuerpo

From Mental Interiority toBodily Exteriority: A Reading of Disgust in Beckett

\begin{abstract}
After the reading of "(W)Horoscope", six poems from Echo's Bones and Other Precipitates and "La mouche", in this article we will try to explain how the concept of disgust articulates the relationship that Samuel Beckett establishes between the outside world the body, the degraded and deciduous- and the inner world of the melancholic subject's mind and thinks about death. This contrast is crossed by different conceptions of disgust which affects not only the mind but also the body. We will analyze disgust concerning
\end{abstract}


food, melancholy, and the deciduous corpse. These three points will provide an example of how the interior and the exterior are connected by the repulsive in Beckett's poems.

Key words: Samuel Beckett, disgust, melancholy, corpse

\section{Los poemas}

"(W)Horoscope" es el primer poema de Beckett, publicado como fruto de un concurso organizado por la casa editora Hours Press en 1930. Fue escrito en el contexto de agotamiento de los modelos de vanguardia, cuando el lugar central de la obra es desplazado por el del escritor. Como señala Lucas Margarit en La poesía de Samuel Beckett. Silencio y fracaso de una poética: "La verdad que la literatura intentaba develar se perdía en la bruma de la crisis" (2006, p. 36). Es un contexto de renuncia, la verdad deja de concebirse como un principio absoluto de conocimiento y el poeta se enfrenta a un lenguaje insuficiente. "Echo's Bones", "The Vulture", "Enueg I", "Enueg II", "Sanies I" y "Sanies II" pertenecen también a la primera etapa de producción poética (desde 1930 a 1937); la cual incluye únicamente poemas escritos en inglés. Estos poemas forman parte del segundo libro de poesía de Beckett: Echo's Bones and Other Precipitates, escritos entre 1931 y 1935 y publicados por Europa Pres; remiten a los restos, lo degradado y lo dejado de lado. Junto con estos poemas se analizará un poema publicado en Les temps Modernes: "La mouche", de la segunda etapa de producción: la transición idiomática (1938-1962). Aquí Beckett continúa con el tema de la mosca ya mencionado en "Serena I", que permite, a partir de ese insecto que evoca el sentimiento de asco, estructurar el pasaje adentro/afuera y observar cómo la temática se sostiene en su producción poética. Los poemas seleccionados proporcionan ejemplos, no solo de cómo el interior y el exterior se encuentran estrechamente relacionados, sino de que ese nexo reside en aquello que repugna.

\section{Nociones sobre el asco}

Paul Rozin, Jonathan Haidt y Clark R. McCauley en "Disgust" rastrean el origen del término "asco" hasta la concepción Darwiniana; que lo define como lo repugnante relacionado al sentido del gusto y a aquello que produzca un sentimiento semejante, como la vista, el olor o el tacto. A la visión de Darwin los autores le añaden la perspectiva de Angyal y destacan: "he held that disgust is revulsion at the prospect of oral incorporation of an offensive object. He identified body waste products as a focus of disgust" (2008, p.757). Angyal incorpora a la definición del asco los desechos corporales, éstos actúan como un recuerdo constante de la caducidad del cuerpo humano y acercan al hombre al animal. Pero la ingesta de alimentos y los desechos del organismo solo son dos de los muchos motivos del asco.

Los autores explican que el sentimiento de repulsión actuaba originalmente como un mecanismo para evitar cualquier daño corporal por la ingesta de alimentos en mal estado; pero con el tiempo se convirtió en un mecanismo para evitar el daño del alma. Se produjo un pasaje de la exterioridad a la interioridad. En "Debates sobre el asco" Linda Ben-Zvi recupera la noción que tiene Aurel Kolnai sobre el asco. El fenomenólogo y filósofo húngaro "amplía la definición de asco hasta incluir en ella la repugnancia moral. Uno de los tipos es el que denomina 'hastío melancólico', que relaciona con la 
saciedad, una sensación análoga a la ingesta de alimentos en exceso" (Ben-Zvi: 2013b, p. 18); Kolnai establece así una clara relación entre el mundo exterior de los sentidos y el interior de las reflexiones del pensamiento.

Karl Rosenkranz también plantea un nexo entre la exterioridad corpórea y la interioridad mental al ubicar el origen de lo asqueroso en una "deformidad que nace de la corrupción física y moral" (1992, p.146); mente y cuerpo están estrechamente relacionados. Beckett expone cómo el hombre debe enfrentarse a la decadencia del cuerpo, la mente, e incluso del mundo. El sentimiento de asco implica el encuentro entre el sujeto y el objeto de la percepción; es aquello que vincula el adentro y el afuera de la mente. En los poemas seleccionados será posible trazar el vínculo entre pensamiento y cuerpo, interior y exterior, lo vivo y lo muerto, gracias a las imágenes repugnantes que evocan las palabras de Beckett. Ben-Zvi advierte que el escritor expone la incapacidad de transmitir con palabras el asco que siente por la experiencia humana, pero es precisamente la exposición de dicha imposibilidad una forma más de mostrar la repugnancia que emana del cuerpo y se concibe en la mente del sujeto en decadencia.

\section{El asco de lo ingerido}

Sentir asco, según lo que propone Kolnai, se encuentra directamente ligado a las observaciones sensoriales. Nos resulta significativo que "(W)Horoscope" comience con una pregunta que hace dudar sobre la percepción de algo comestible: "What's that? / An egg?" (vv. 1-2). La pregunta implicará una reflexión sobre la imposibilidad de conocer el mundo que rodea al sujeto y de poner ese mundo en palabras. El personaje de Descartes en el poema está inmóvil y medita. Sus sentidos no le alcanzan para encontrar una respuesta a su pregunta y debe dejarse llevar por las divagaciones de su mente. Su ignorancia no le permite entender qué va a ingerir y mucho menos enunciarlo. Podemos concebir sus meditaciones como una búsqueda de conocimiento destinada al fracaso.

Lo que sucede en el comienzo del poema es la imposibilidad de poder nombrar lo que se tiene frente a los ojos. Como señala Ben-Zvi: "las emociones están vinculadas con el modo en que se habla de ellas, lo lingüístico es un componente del asco porque es un fenómeno social y cultural" (Ben-Zvi: 2013b, p.19). Las carencias del lenguaje también se manifiestan en "Echo's Bones", donde, desde el título del poema, se remite a la repetición de un sonido que nadie escucha, a palabras que no se oyen. Se establece así, como señala Margarit, una relación entre la voz y el cuerpo, las palabras y el mundo. En "Beckett y Blanchot: el murmullo de la crítica" Margarit remite a una "realidad encerrada en la autopercepción del pensamiento" (Margarit: 2002); el poeta expone la problemática de cómo expresar a partir de un lenguaje que se encuentra agotado, que no se corresponde a la experiencia y que es impuesto. Y por ello consideramos que el poeta, como Descartes, se ve encerrado en las cavilaciones de su propio pensamiento y necesita entrar en contacto con el afuera.

Estas reflexiones nos permiten establecer una relación directa entre lo que no se dice y la necesidad de recurrir al asco para expresarlo. Como nada se puede decir, solo queda mostrarlo y para ello Beckett selecciona las imágenes más abyectas. Lo feo realiza su aparición en el arte, como señala Rosenkranz, como un síndrome de la época. Kristeva destaca en "Sobre la abyección", que éstas imágenes desagradables tienen "un polo de atracción y de repulsión" (1988, p.7). La primera relación con el exterior, con la percepción o, más específicamente, duda sobre la percepción, de lo asqueroso que debe llamarnos la atención es aquella que se produce a través de los alimentos. La imagen del huevo es la imagen de lo putrefacto y degradado, que recuerda la vulnerabilidad del cuerpo y su proceso de declinación hacia la muerte. Esta imagen reaparece en los 
poemas de Beckett, como cuando se mencionan "red eggs" (v. 4) en "Sanies II" en relación a la enfermedad y las gallinas infectadas ("verminous hens" (v. 50)) de "Enueg I": son lo alimenticio pero contaminado. A partir de dichas consideraciones entendemos que el hecho de ingerir un alimento implica traspasar la barrera que existe entre el interior y el exterior del cuerpo, incorporar ese objeto putrefacto en el organismo, convirtiéndolo en parte de uno mismo.

Descartes reflexiona sobre lo que implica ingerir algo. La comida del desayuno se transforma en una parodia cuando se mezclan las referencias eruditas y teológicas con las reflexiones ordinarias: "So we drink Him and eat Him" (v. 59), evocando la celebración de la eucaristía, para luego mencionar un vino y un pan de consumo corriente: "and the watery Beaune and the stale cubes of Hovis" (v. 60). Consideramos al desayuno repugnante como un disparador de múltiples reflexiones sobre aquello que ingresa en el organismo, tanto material como intelectual. El sentimiento de asco conecta al sujeto con el objeto que intenta percibir y permite exponer lo que el lenguaje fracasa en enunciar.

En el poema "(W)Horoscope" el personaje de Descartes espera ante su desayuno. Beckett no muestra al filósofo, sino a un sujeto corriente con un cuerpo que siente y teme; se dirige al afuera para percibir el mundo que lo rodea pero luego se ensimisma. Descartes se encuentra inmóvil porque medita, deja que su pensamiento fluya libremente mientras espera su muerte. La aceptación de la caducidad corresponde con la ingesta de su desayuno, de ese huevo-pollito compuesto de "White and yolk and feathers" (v. 93); hay un entrecruzamiento entre las partes del huevo que hace imposible determinar si el pollito ya se formó. Se come aquello que simboliza la detención de la vida. El huevo se transformaría en pollito pero en el poema se muestra algo intermedio. Como plantea Kristeva, lo abyecto es "lo ambiguo, lo mixto" (1988, p.11), aquello que no puede ser definido. Rosenkranz propone que el objeto se torna repugnante "sólo cuando desmiembra la totalidad de la forma" (1992, p.133), es "lo muerto feo" (1992, p.138) por su falta de determinación.

$\mathrm{Al}$ alimento también lo debemos relacionar con aquello que en algún tiempo fue feliz, como sucede en "Sanies I", recuerda al pasado infantil y alegre de la niñez: "for mamma papa chicken and ham" (v. 19). En "Enueg II" la mermelada, posible evocación de lo dulce, es el alimento en el cual reside el viejo corazón del poeta que añora una época mejor a la cual no se puede regresar: "heart in marmalade / smoke more fruit / the old heart the old heart" (vv. 17- 19). En "(W)Horoscope" Para describir al ser amado también se hace referencia a aquello que se ingiere. Francine es para su padre: "my precious fruit" (v. 1).

El fruto tiene una doble connotación: el alimento, y la parte de la planta en que se transforma el ovario de la flor después de la fecundación. La hija de Descartes es descripta como aquello donde se origina la vida y por ello contrasta con el huevo amorfo que remite a la existencia interrumpida. Surge la pregunta sobre cuándo comienza la vida. Las reflexiones del filósofo sobre su caducidad se encuentran ejemplificadas en el alimento que tiene ante sí: pensar en la muerte produce la misma repugnancia que alimentarse de ese ser amorfo. Las transformaciones del huevo-pollito remiten a las transformaciones de una idea en otra en el fluir de la consciencia del personaje de Descartes. El pollito que el filósofo tiene ante sí produce repugnancia porque hay algo de vida en aquello que debería ya estar muerto. La mera noción de ingerir algo que no se encuentra del todo muerto evoca el sentimiento de náusea debido a la antigua creencia de que quien se alimenta incorpora las propiedades de aquello que ingiere, como plantean los autores de "Disgust": "You are what you eat" (2008, p.759).

En "The Vulture" se presenta al alimento como un resto. Al buitre, como al hombre, lo guía su instinto: "dragging his hunger through the sky" (v. 1). Podemos observar cómo Beckett rompe con la distinción entre el hombre y el animal y por ello produce 
un sentimiento de repugnancia: "Anything that reminds us that we are animals elicits disgust" (Rozin, et al.: 2008, p.761). Luego de recorrer todo el cielo y la tierra, el buitre solo encuentra desechos; a lo único que el buitre y el hombre pueden acceder es a una comida en mal estado: "earth and sky be offal" (v. 6).

Los restos de los que se alimenta el buitre son un conjunto amorfo de las partes de un cuerpo en descomposición. La ingesta del alimento que resulta repulsivo por su ambigüedad remite a lo que retoma Ben-Zvi de Miller: "lo que causa asco es una verdad que los humanos se esfuerzan por esquivar" (Ben-Zvi: 2013b, p.19). En "Echo's Bones" es el cuerpo del hombre aquello que se convierte en alimento para los gusanos. Las digresiones de Descartes frente a su desayuno solo postergan lo inevitable, su muerte y el buitre se sacia con lo único que queda para el hombre, los restos. Se lleva a cabo una aceptación mental de la caducidad corporal y de la condición del hombre en el mundo como quien solo puede acceder a los restos y como quien se convertirá en un resto más. De esta forma demostramos cómo mente y cuerpo se unifican al asimilar lo desagradable, aceptando dicha degradación.

\section{Asco y melancolía}

La oscilación que se produce, el ir y venir del pensamiento, hasta llegar a la ingesta del desayuno en "(W)Horoscope", nos hace pensar en el sujeto melancólico atrapado en la inmovilidad. Como sucede en "The Vulture", donde se produce un merodeo sin llegar a la acción y todo aparenta transcurrir en el interior del cráneo: "dragging his hunger through the sky / of my skull shell of sky and earth" (vv. 1-2). La melancolía recuerda a la teoría renacentista de los humores. El sujeto melancólico era considerado inestable porque en él residía la bilis negra; se lo relacionaba al filósofo o al artista por la oscilación de sus estados de ánimo. Montes, como destaca Noelia Billi, considera a la melancolía presente en los poemas de Beckett como un "mal epocal" (Billi: 2020, p.83), vinculado a la ansiedad de la sociedad moderna. El cráneo es aquello que recubre la realidad de cada sujeto y le permite vivir en su época. Margarit señala: "en Beckett, lo poético se ubica en el fracaso y por ello el yo poético se repliega en su mundo interior, la caja craneal" (2014, p.29). El solipsismo de la obra de Beckett reside en que todo, incluso la realidad que habita el sujeto, es solo una prefiguración de su mente.

El contraste entre el adentro y el afuera es muy claro en "La mouche" donde se presentan el espacio interior y el exterior estructurados a partir del vidrio, siguiendo lo propuesto por Margarit: "El vidrio es la superficie que separa esos dos espacios, el del poeta y el mundo" (2006, p.157), "La estructura del vidrio representa el recinto craneal del poeta y la mosca" (Margarit: 2006, p.172). La mosca se halla "sous mon pouce impuissant" (v. 9), inmovilizada, indefensa, al igual que se encuentra el poeta, atrapado en el ir y venir de su pensamiento, el buitre en su deambular por el cielo y Descartes frente a su desayuno. Yoshiki Tajiri destaca, como una característica de los poemas de Beckett, el sentimiento de encontrarse en un espacio interior "the womb and the skull" (2007, p.54). El cielo y la tierra que recorre el buitre "sirven para englobar toda posible percepción del mundo" (Margarit: 2006, p.253) en su mente. La relación entre el mundo exterior y el interior no es confiable porque se encuentra atravesada por el sujeto, pero advertimos en los ejemplos enunciados cómo lo degradado provee ese nexo que parece ausente. El buitre es "mocked by a tissue that may not serve" (v. 5); su percepción choca con la realidad que le muestra un objeto inservible en lugar de comida, de la misma forma que el pollito por formarse hace que Descartes enfrente su caducidad.

Rosenkranz identifica al aburrimiento como una causa del asco: "Lo muerto, lo vacío, lo frío por su falta de libre distinción, de desarrollo, se convierte en algo sin interés, 
aburrido. Lo aburrido es feo; o más bien, la fealdad de lo muerto, lo vacío, de lo tautológico" (1992, p.140), es aquello que produce repulsión. Advertimos cómo el sentimiento de asco no solo conecta al sujeto con el exterior sino que está siempre presente en sus cavilaciones por ser producto del hastío que le produce vivir. El sujeto debe salir al mundo y enfrentarse a la realidad, pero al hacerlo ve magnificados los elementos repulsivos. Como señala Ben- Zvi: "Los personajes de Beckett están quietos y desde esa quietud perciben su degradación” (2013a, p.15).

Debido a que el sujeto melancólico está encerrado en su interior surgen "descripciones del asco que emanan del hastío" (Ben-Zvi: 2013b, p.19). Como señala Montes: el "dolor, el asco y el hastío desvía de la palabra rumiada y proyecta hacia un afuera en el que se juegan las vicisitudes del cuerpo" (Montes: 2014, p.35). El pensamiento desemboca en lo corpóreo y ambos convergen en el sentimiento de repulsión. El fluir de conciencia del personaje de Descartes es una meditación que intenta llegar al conocimiento; se deja arrastrar por sus cavilaciones hasta que no puede alcanzar nada más y debe hacer uso de su aparato sensitivo. Como sucede en "Echo's Bones", se presenta una condensación de sentidos, sonidos sordos, hedor y temor que establece un nexo entre lo físico y lo mental. Y en "The Vulture", el animal se deja guiar por sus sentidos hasta llegar a la aceptación de que su único alimento será algo en descomposición.

Lo abyecto, a partir de lo propuesto por Kristeva, no es solo lo sucio o caduco, sino también todo aquello que "perturba una identidad, un sistema, un orden" (1988, p.11). El aburrimiento lleva a la repulsión, producida por pensar en el absurdo de una existencia desordenada. Beckett muestra la dificultad de salir de la mente, del lenguaje. El sujeto no puede expresar ni conocer del todo el mundo. Vivir, como propone Margarit, es una pasión inútil. Estar vivo implica un enfrentamiento constante con lo degradado: por el mero hecho de estar en movimiento, la vida se corrompe y lo único que puede sostener la existencia del sujeto es su pensamiento. Cuando el cuerpo se detiene, es cuando la mente más se mueve. El sujeto debe enfrentarse al vacío que le exponen sus cavilaciones. La angustia del poeta se produce porque pensamiento y acto no pueden llegar a una realización. El poeta enuncia para escucharse en su discurso y así intentar construir su identidad pero, como señala Margarit, como el lenguaje no otorga ninguna certeza, el autoconocimiento es imposible. Debido al tiempo en el que vive, el sujeto solo puede fracasar.

La mirada más universal sobre la decadencia social que T. S. Eliot propone en The waste Land (1922) tiene sus similitudes con las escenas que Beckett muestra en sus poemas. La diferencia reside en que Beckett no concibe la posibilidad de poder volver a un pasado mejor. Como Eliot, se mantiene escéptico respecto al progreso pero expone una mirada individual. En los poemas "Enueg I", "Enueg II", "Sanies I" y "Sanies II" el asco y la decadencia son los que siente y experimenta el sujeto melancólico, y no los de toda la humanidad. Beckett presenta a una Dublín y una Francia en ruinas mediante el uso de imágenes abyectas.

"Enueg I" comienza haciendo referencia a la enfermedad de la amada que lleva al sujeto a alejarse del hospital y recorrer la ciudad: "Exeo in a spasm" (v. 1). El verbo "exeo" significa "salgo" y, como explica Margarit, el yo poético se presenta "ligado con una acción que implica movimiento, un movimiento de huida" (2006, p.26). A diferencia de lo que sucede en "(W)Horoscope", "La mouche" y "The Vulture", que remiten a la inmovilidad o al dar vueltas en círculos, en "Enueg I", "Enueg II", "Sanies I" y "Sanies II" sí hay movimiento físico del sujeto. En "Sanies I” el yo poético se desplaza hasta llegar a lo que fue su hogar. La felicidad de los días pasados es reemplazada por la imagen de la tumba: "warm Grave" (v. 20). Y en "Sanies II" el sujeto se dirige a un burdel. El espacio que rodea al yo poético espeja la muerte y la decadencia de su entorno: la agonía de la amada en "Enueg I" refleja la agonía del mundo; la felicidad de tiempos mejores ha muerto y solo se puede acudir a un desagradable burdel de París como 
expresa el sujeto en "Sanies II": "there was a happy land / the American Bar / in Rue Mouffetard" (vv. 1-3). Converge el miedo a la muerte con la sensación de no poder resistir. A pesar de encontrarse en movimiento, el sujeto no puede eludir el estar en el mundo y debe continuar aun sabiendo que está destinado a fracasar. Si el sujeto se detuviera, finalizarían los poemas.

La imagen del cráneo aparece en "Enueg I": "my skull sullenly" (v. 12), remitiendo a la interioridad de la mente como se mencionó respecto de "(W)Horoscope", "La mouche" $y$ "The Vulture". Pero, en el verso siguiente, ya se evoca una imagen repugnante, que crea la conexión con el afuera: "clot of anger" (v. 13); el sujeto sale disparado hacia Dublín como si fuera un coágulo de sangre. La ciudad está enlazada con las reflexiones de la mente del yo poético a través de las evocaciones del sentimiento de asco, como es posible observar en los versos 56 y 57: "soaking up the tattered sky like an ink of pestilence, / in my skull the wind going fetid". El cráneo, la mente, siente los hedores de la ciudad que se pudre.

Desde los primeros versos del poema, en "Enueg II", se establece un paralelismo entre las expresiones del rostro que reflejan las cavilaciones de la mente y el mundo que rodea al yo poético: "world world world world / and the face grave / cloud against the evening" (vv. 1-3). El exterior y el interior están vinculados porque el cielo se oscurece como lo hace la mente del sujeto al percibir la decadencia de la ciudad. El yo poético percibe al mundo desde su mirada cargada de dolor por la pérdida de su amada. Por este motivo, el sujeto solo observa una realidad parcial. A pesar de que la naturaleza que lo rodea remite a lo vivo con los tulipanes: "goggling at the tulips of the evening" (v. 23), éstos solo pueden ser evocados como algo repulsivo y cercano a la muerte: "shining round the corner like an anthrax" (v. 25). En "Enueg I", "Enueg II", "Sanies I" y "Sanies II" la interioridad sale hacia afuera como cosas asquerosas, los poemas actúan como esputo de la interioridad y son un resto más de la ciudad en ruinas.

El sujeto debe interactuar con el objeto, salir del encierro de la mente y aceptar su corporeidad. Montes destaca que "Es posible afirmar que en Beckett el cuerpo es el lugar en el que se juegan para el sujeto melancólico las extenuantes batallas entre los imperativos de una mente" (Montes: 2014, p.36). Como se observó en los poemas, el sujeto se ve obligado a salir del espacio interior, el cráneo, y enfrentarse a su visión del mundo. Este nexo entre mente y mundo es repulsivo y está atravesado por lo corpóreo. El poeta obtiene el material para su poesía de los restos, de la carroña del mundo.

\section{Asco y cuerpo}

Lo que se concibe en la mente contrasta con las capacidades del cuerpo. El pensamiento sucede fuera del tiempo, extiende la existencia al infinito; mientras que el cuerpo recuerda a la caducidad. Se observa en el cuerpo de la mosca: "ventre à terre/ sanglée dans ses boyaux noirs / antennes affloées ailes liées / pattes crochues bouche suçant à vide" (vv. 4-7); es una corporalidad descripta de forma desagradable que la inmoviliza. Conectarse con el afuera es aceptar el paso del tiempo, el ir hacia el cadáver que recuerda, como expone Kristeva: "Me encuentro en los límites de mi condición de viviente" (1988, p.10), "el cadáver, el más repugnante de los desechos, es un límite que lo ha invadido todo" (p.10), "es el colmo de la abyección. Es la muerte infestando la vida." (p.11), es la mosca intentando librarse de la presión del pulgar; lo corpóreo que invade el pensamiento, conectándose con el exterior.

Como propone Ben-Zvi, Beckett nos enfrenta a una sintaxis de la debilidad, "una sintaxis del asco elaborada desde un conocimiento experimental de las debilidades 
y enfermedades de su cuerpo" (Ben-Zvi: 2013b, p.20). En "(W)Horoscope” retoma la polémica Descartes-Harvey en los versos 29-41, conflicto en la época sobre si la sangre y el corazón están en movimiento. La hija de Descartes, Francine, estaba enferma, muere a los 6 años. En la mente de Descartes se produce la relación entre la enfermedad de su hija con Harvey porque ésta tenía un problema en el corazón. Describe la apariencia física de la niña intentando atenuar el efecto repulsivo de la manifestación física de su enfermedad, pero no lo logra y produce un efecto igual de desagradable: "Her Little flayed epidermis and scarlet tonsils!" (v. 32). De esta forma se puede observar cómo el fluir de conciencia lleva al filósofo a pensar en la degradación del cuerpo por la enfermedad. En "Enueg II", el deambular sin rumbo del yo poético lo lleva a experimentar el sufrimiento corporal análogo a la Vía Dolorosa, el recorrido de Cristo hacia la Cruz, como explica Margarit en su tesis. Dejarse llevar por las divagaciones de la mente desemboca en la consciencia de lo material.

Ben-Zvi destaca: "el cuerpo físico descomponiéndose está siempre ahî" (Ben-Zvi: 2013a, p.15), cuanto el sujeto más se deja llevar por el pensamiento más cae en las meditaciones sobre la muerte. Tajiri explica que Beckett hereda de Descartes una actitud de observador externo respecto del cuerpo, concibiéndolo como una máquina ensamblada por partes. El crítico observa cómo Beckett percibe los órganos como prótesis que forman parte de esa maquinaria deficiente que no deja de descomponerse. En "Echo’s Bones" nos encontramos con imágenes abyectas donde se destaca cómo cae la carne mientras ésta se descompone y es consumida por los gusanos: "as the flesh falls [...] taken by the maggots" (vv. 2 y 5). En el poema se establece nuevamente el paralelo entre el afuera y el adentro; en el exterior, el cuerpo se descompone, mientras que en el interior, se reflexiona sobre "sense and nonsense" (v. 4) de esa caducidad.

"Sanies I" y "Sanies II" remiten al asco de la descomposición corpórea ya desde el título: “sanies' -supuración fétida mezclada con suero y sangre" (Ben-Zvi: 2013b, p.21). Ambos poemas presentan imágenes sobre los fluidos y las secreciones del cuerpo que recuerdan a su caducidad. A partir de lo propuesto por Margarit, los poemas exponen "el sufrimiento personal que genera la existencia" (2006, p.105). Como explica Ben-Zvi, Beckett muestra el funcionamiento interno del cuerpo como sus emisiones externas: "lo que hace el cuerpo -comer, orinar, defecar, vomitar, sangrar y procrear; lo que el cuerpo conoce -su propio destino físico y su finitud" (2013b, p.22). El cuerpo permite el intercambio con el exterior a través de sus emanaciones y secreciones y recuerda al hombre que su existencia es limitada.

Tajiri señala cómo en la obra de Beckett es posible advertir una obsesión con los "orifices and their exchangeability" (2007, p.54); el cuerpo se conecta con el afuera a través de las secreciones de sus orificios. "Enueg I" comienza con la imagen "red sputum" (v. 2), que remite a la enfermedad y a cómo ésta entra en contacto con el mundo. En sintonía con esta imagen está la de las gallinas infectadas: "grey verminous hens" (v. 50), que, nuevamente, refleja la exterioridad de la enfermedad: la infección que se muestra en la superficie del cuerpo y repugna. Luego se hace referencia al himen: "jungle hymen" (v. 47), evocando la membrana mucosa que rodea la apertura vaginal y que puede romperse al ser penetrada. La mención del vómito ("grey spew of the sewer" (v. 71)) es un último ejemplo de cómo Beckett establece el nexo con el exterior utilizando imágenes desagradables que recuerdan a la materialidad del hombre y su necesidad de producir o dejar ingresar desechos para conectarse con el afuera.

Como explica Tajiri, las fronteras entre el cuerpo y el mundo material y exterior se problematizan y se vuelven ambiguas. Los orificios conectan al hombre con la ciudad y las imágenes de los desperdicios corporales son aplicadas para describir a una Dublín 
en ruinas en "Enueg I" y "Enueg II". En "Sanies I" y "Sanies II" la ciudad es París y no Dublín, pero el procedimiento es el mismo. El espacio y lo que el yo poético observa en él es descripto utilizado imágenes de la corporeidad, por ejemplo "tires bleeding voiding zeep the highway" (v. 6).

En estos dos poemas también se nombran los orificios ("all heaven in the sphincter" (v. 7)) como la forma de comunicarse con el exterior. Beckett hace mención en "Sanies I" al nacimiento, un ejemplo claro de pasaje desagradable del interior al exterior, y lo relaciona a la desgracia que implica vivir en un mundo en decadencia. El erotismo del poema expone el deterioro de las relaciones amorosas. El disgusto surge de la aversión a la reproducción, la cual remite a los orificios antes mencionados y a la incesante repetición de una existencia destinada al fracaso. El sujeto ingresa al mundo de forma sucia: "for the midwife he is gory" (v. 29) pero Beckett contrasta la visión objetiva de la comadrona con la subjetiva del padre que ve los desechos corporales producidos en el momento del parto con orgullo y sin repulsión. Beckett expone el asco que implica la existencia humana pero que el hombre se niega a aceptar, tal como lo hace el padre en el poema.

En "Sanies II" las imágenes son las del burdel y la relación entre el adentro y el afuera se produce por los orificios infectados: "I have a dirty I say henorrhoids" (v. 5). El debilitamiento del cuerpo enfermo concuerda con el olor de las prendas de las que se despoja el sujeto para llevar a cabo el acto sexual. Lo viejo y oloroso está siempre presente: "stinking old suit" (v. 10), "stinking old trousers" (v. 13), anticipando el intercambio de los cuerpos. El cuerpo permite articular el pasaje del interior del pensamiento a la exterioridad. Salir del encierro de la mente y superar la inmovilidad que el pensar produce implica atravesar los orificios corporales y aceptar el intercambio con el mundo exterior. Por lo tanto podemos afirmar que las secreciones del hombre le permiten entrar en contacto con su caducidad.

\section{Conclusión}

El análisis de los poemas considerados para este trabajo nos permite demostrar cómo el sentimiento de asco establece el vínculo entre el sujeto y el mundo que lo rodea. El sujeto melancólico que sufre en el interior de su mente entra en contacto con el afuera gracias a aquello que le produce repulsión: lo material y corpóreo. Beckett expone la imposibilidad de colocar el pensamiento en palabras, de enunciar aquello que se percibe con los sentidos, cómo se observó en "Echo's Bones" y en "(W)Horoscope". Para expresar lo que no se puede decir, el poeta recurre a lo abyecto, según lo propuesto por Kristeva, y muestra aquello que el sujeto se esfuerza por ocultar. A partir de estas consideraciones resulta claro percibir cómo la exposición de la caducidad humana que realiza el poeta conecta a la mente con el exterior.

Este procedimiento se pudo apreciar a partir de tres ejes. El poeta emplea imágenes del asco en relación a lo ingerido, recurriendo a las primeras manifestaciones del asco, según lo propuesto por Paul Rozin, Jonathan Haidt y Clark R. McCauley. Al mostrar la ingesta de lo repugnante y amorfo, Beckett expresa la imposibilidad del hombre de alimentarse de algo que no sea carroña. La mente y el cuerpo convergen en la aceptación de esta condición humana. Incluso el poeta solo puede alimentar su poesía con restos. Luego se analizó el asco producido por el aburrimiento del sujeto melancólico que se encierra en su mente. Las representaciones del interior de la caja craneal chocan con el mundo que el sujeto tiene ante sí. El exterior consiste en una ciudad en decadencia que le recuerda al hombre su propia materialidad degradada. Por último, se consideró la relación entre el sentimiento de repulsión y el cuerpo, partiendo de la noción del 
cuerpo como una máquina, explicado por Tajiri. Pudimos identificar cómo Beckett coloca en primer plano las secreciones corporales como el nexo con el mundo y de esa forma recuerda lo corpóreo y caduco de la existencia humana.

Los tres ejes considerados solo brindan una humilde aproximación al vínculo que puede establecerse entre el interior y el exterior mediante el sentimiento de asco en la obra poética de Beckett. Los poemas seleccionados permiten ejemplificar, como muchos otros del autor, la forma en que el hombre entra en contacto con el mundo. 


\section{Q Bibliografía}

»Beckett, S. (2007). “(W)Horoscope”, “Echo'sBones”, “TheVulture”, “Enueg I", “Enueg II", "Sanies I", "Sanies II" y "La mouche" en Samuel Beckett. Obra poética completa. Madrid: Ediciones Hiperión.

»Ben-Zvi, L. (2013). "Beckett y la teoría del asco" (conferencia) en Beckettiana, № 12. Buenos Aires: Sección de Literatura en Lenguas Extranjeras, Instituto de Filología y Literaturas Hispánicas “Dr. Amado Alonso", Facultad de Filosofía y Letras, Universidad de Buenos Aires (pp. 9-16). Edición a cargo de la Lic. Elina Montes.

》Ben-Zvi, L. (2013). “Debates sobre el asco” en Beckettiana, № 12. Buenos Aires: Sección de Literatura en Lenguas Extranjeras, Instituto de Filología y Literaturas Hispánicas “Dr. Amado Alonso", Facultad de Filosofía y Letras, Universidad de Buenos Aires (pp. 17-24). Edición a cargo de la Lic. Elina Montes.

"Billi, N. (2020). “Más acá del lenguaje. Melancolía e inmediatez del cuerpo en la obra de Samuel Beckett” Elina Montes (2019) en Beckettiana, № 17. Buenos Aires (pp. 82-84).

» Kristeva, J. (1988). “Sobre la abyección" en Poderes de la perversión. Ensayo sobre Louis-Ferdinand Céline: Buenos Aires, Catálogos.

»Margarit, L. D. (2002). "Beckett y Blanchot. El murmullo de la crítica”. Revista Beckettiana. [Online] Disponible en http://www.filo.uba.ar/contenidos/ carreras/letras/catedras/litinglesa/sitio/home_beckettiana [20/02/2021]

" Margarit, L. D. (2006). "Capítulo II. Echo's Bones and Other Precipitates" y "Capítulo IV. Alternancias poéticas. Douze Poèmes: La mosca" en La poesía de Samuel Beckett. Silencio y fracaso de una poética, Tesis doctoral, Universidad de Buenos Aires.

" Margarit, L. D. (2014). "Samuel Beckett y Georg Trakl: dos poéticas del desencanto” en Beckettiana, Nº 13 . Buenos Aires (pp. 17-24).

»Montes, E. (2014). “Un montón de cosas repugnantes: rechazo y melancolía en la obra de Samuel Beckett" en Beckettiana, $^{\circ} 13$.Buenos Aires: Sección de Literatura en Lenguas Extranjeras, Instituto de Filología y Literaturas Hispánicas “Dr. Amado Alonso", Facultad de Filosofía y Letras, Universidad de Buenos Aires. Edición a cargo de la Lic. Elina Montes (pp.33-40).

"Montes, E. (2017). “Los cuerpos melancólicos de Samuel Beckett” en Segundas jornadas de literatura inglesa. 110 años del nacimiento de Samuel Beckett". Editores Argentinos.

»Rosenkranz, K. (1992). “Tercera sección. B. Lo repugnante” en Estética de lo feo. Julio Ollero Editor S.A.

» Rozin, P., Haidt, J. \& McCauley, C.R. (2008). “Disgust.” En Handbook ofEmotions, edited by Michael Lewis, Jeanette M. Haviland-Jones, and Lisa Feldman Barrett. Nueva York: Guilford.

» Tajiri, Y. (2007). "The Question of Boundaries" en Samuel Beckett and the Prosthetic Body. The Organs and Senses in Modernism. Nueva York: Palgrave. 
